\title{
RELAÇÃO COVID-19 X EVASÃO NO ENSINO SUPERIOR LATO SENSU NA MODALIDADE EAD
}

\author{
Dayane Priscila Bicalho de Souza \\ UFVJM \\ dayanepriscila90@hotmail.com
}

\begin{abstract}
RESUMO
O COVID-19 vem afetando vários ramos no mundo todo. Afim de analisar a educação a distância no Brasil, buscou-se identificar a relação entre casos confirmados de COVID-19 e evasão de alunos dentre as cidades e regiões brasileiras. A coleta de dados sobre evasão foi realizada em uma Instituição de Ensino Superior a qual oferta cursos na modalidade EaD em âmbito nacional e os dados sobre Covid-19 foram extraídos do site Coronavírus Brasil. A pesquisa trouxe dados interessantes sobre a relação COVID-19 x Evasão relacionados aos números de desempregos no Brasil podendo destacar a situação financeira dos alunos um dos principais motivos que o leva a evadir. Destaca-se que futuras pesquisas poderão ser realizadas com base no fundamento deste trabalho.
\end{abstract}

Palavras-chave: Pandemia. Evasão de alunos. Desemprego 


\title{
RATIO COVID-19 X DROPOUT IN HIGHER EDUCATION LATO SENSU IN THE EAD MODALITY
}

\begin{abstract}
COVID-19 has been affecting several branches worldwide. In order to analyze distance education in Brazil, we sought to identify the relationship between confirmed cases of COVID19 and dropout rates among Brazilian cities and regions. Evasion data collection was carried out at a Higher Education Institution which offers distance education courses nationwide and data on Covid-19 were extracted from the Coronavirus Brazil website. The research brought interesting data on the relationship between COVID-19 $\times$ Evasion related to the number of unemployed in Brazil, highlighting the students' financial situation, one of the main reasons that leads them to evade. It is noteworthy that future research may be carried out based on the basis of this work.
\end{abstract}

Keywords: Pandemic. Dropout of students. Unemployment 


\section{INTRODUÇÃO}

Pesquisas relacionadas ao COVID-19 vêm sendo realizadas em todo mundo e a cada dia. De acordo com o site Coronavírus Brasil ${ }^{1}$ o COVID-19 é uma doença causada pelo Coronavírus que apresenta uma relação de infecções assintomáticas a quadros graves. Além da saúde, essa doença vem impactando também a economia mundial e brasileira, conforme dados levantados nos últimos meses decorrente ao surgimento da COVID-19.De acordo com a temática, verificou-se publicações brasileiras relacionadas aos impactos causados pela pandemia, sendo os assuntos mais citados: economia e educação.

Dias e Pinto (2020) citam que o confinamento fez com que várias atividades sofressem com a paralisação devido ao COVID-19, inclusive escolas públicas e privadas do ensino básico ao ensino superior. Os autores também ressaltam que secretários e gestores devem pensar na saúde mental dos professores, pois a exaustão mental destes pode interferir no progresso de ensino podendo interferir na evasão.

Entende-se que a evasão é uma variável constante, presente e praticamente inevitável, contudo, uma análise aprofundada no cenário atual será discutida para confirmar os principais fatores que estão levando os alunos a evadirem dos cursos com maior frequência em relação a pandemia.

No entanto, o presente trabalho apresenta uma análise da relação entre evasão de alunos do ensino superior lato sensu e o número de casos de COVID-19 em cidades brasileiras. A coleta de dados de alunos evadidos no período da pandemia foi realizada através de banco de dados de uma Instituição de Ensino Superior (IES), a qual oferta esses cursos na modalidade de Ensino a Distância (EaD). A Instituição e a modalidade EaD foram escolhidas por conter alunos espalhados por toda a região brasileira. Os dados sobre a COVID-19 foram extraídos da base de dados disponibilizada e atualizada diariamente pelo Coronavírus Brasil.

Através da análise desse conjunto de dados, buscou-se identificar a relação entre Covid-19 e evasão no ensino superior de cursos da modalidade EaD (lato sensu) de uma instituição de ensino privada, uma vez que, por serem mais acessíveis e alcançarem um

\footnotetext{
${ }^{1}$ https://covid.saude.gov.br
} 
número maior de pessoas ao contrário de cursos presenciais, esses alunos já estão adaptados a estudar em casa com o apoio de recursos tecnológicos.

\section{REFERENCIAL TEÓRICO}

A necessidade pelo distanciamento social proporcionou um novo desafio para o mundo. Seja no âmbito profissional ou educacional, a continuidade dos processos tem sido afetada diretamente. Consequentemente, na educação não fora diferente. O ensino remoto ganhou espaço em tempos de pandemia, requerendo a adaptabilidade e uso de metodologias e práticas pedagógicas diferentes das salas de aula tradicionais. Todavia, não se pode assegurar que o processo de absorção e conhecimento seja o mesmo (BEZERRA et al., 2020).

No ensino a distância, as dificuldades encontradas durante a pandemia se diferem em boa parte do ensino presencial. Apesar da necessidade de adaptação, vantagens podem ser observadas com a evolução das Tecnologias Digitais da Informação e Comunicação (TDIC's) no EaD. O ensino remoto pode se adaptar a uma forma de ensino similar fazendo uso de ferramentas já utilizadas previamente pelo mesmo, afinal, seu crescimento propiciou o desenvolvimento de novos sistemas e ferramentas a serem utilizadas ao longo dos últimos anos (ABED, 2018).

Foi realizada uma busca por trabalhos relacionados ao tema, utilizando as palavraschave: evasão, EaD, impactos na educação, Ensino Superior e Covid-19. Destaca-se a seguir os principais trabalhos encontrados referentes à busca proposta.

Gomes e Bryto (2018) realizaram uma pesquisa com abordagem qualitativa e quantitativa, onde utilizaram entrevistas com alunos de cursos presenciais com o objetivo de adquirir informações que apontasse os principais fatores para a evasão de alunos de cursos. Os autores destacaram fatores econômicos como principais motivos a não permanência em cursos presenciais.

Maciel et al. (2019) desvelaram publicações como teses, dissertações e artigos, cujos objetivos discorram sobre permanência e evasão na educação superior divulgadas. Os analisados trazem em seus conteúdos assuntos concentrados em evasão em um conjunto de cursos, evasão na EaD e evasão em um curso de uma instituição específica a evasão. Os autores por fim descreveram que os fatores adaptação, rendimento e vivências acadêmicas no ensino superior foram fatores para o abandono do curso. 
Matta et al. (2017) realizaram uma revisão de artigos publicados entre 2005 e 2015, referentes à adaptação universitária relacionada às vivências acadêmicas, afim de investigar o nível de adaptação, rendimento acadêmico e permanência de graduandos de engenharia de uma universidade federal do estado do Paraná. Conclui-se que os relacionamentos interpessoais e o apoio acadêmico podem favorecer o rendimento e adiar a evasão.

O objetivo da pesquisa de Silva e Santos (2017) foi verificar o efeito da concessão de bolsas do PROUNI e FIES na contenção da evasão através de pesquisa quantitativa com dados disponíveis pelo BRASIL (2015d) e INEP (2015). Foi utilizada a técnica de análise de painéis com o software GRETL. A evasão foi obtida ao nível dos Estados e Distrito. Foram coletados dados da evasão de 2005 a 2013 concluindo-se que gestores públicos podem direcionar políticas públicas que tenham eficácia na contenção da evasão haja vista seus efeitos adversos em relação à ociosidade de recursos e perda de receita.

Júnior et al. (2016) realizaram uma pesquisa com o objetivo de identificar os fatores da evasão no curso de Administração Pública a Distância da Universidade Federal de Santa Catarina (UFSC), nas turmas denominadas PNAP 1 e PNAP 2. O trabalho analisou as causas de evasão nesse curso, através de turmas com ingresso em 2009 e 2011, intituladas respectivamente PNAP1 e PNAP2. A amostra foi definida pelo número de respostas retornadas do questionário enviado. No PNAP1 retornaram 37 respostas e no PNAP2 retornaram 12. Além da questão pessoal, os fatores didático-pedagógicos e institucionais estiveram mais presentes como causas da evasão. Concluiu-se também que nas duas turmas, constataram-se dificuldades dos graduandos em se adaptar à modalidade a distância.

Gonçalves et al. (2020) estudaram sobre a evasão nos cursos de graduação presencial do campus Agrícola, utilizando-se quatro variáveis: sexo, idade ao ingressar no curso, renda per capta e cor/raça no IFES em Alegre. Este estudo apontou como perfil do aluno evadido ter mais de 30 anos de idade, ser da cor branca com renda per capta inferior a 0,5 Saláriosmínimos, independente do sexo.

Guerra et al. (2019) objetivaram analisar os fatores que contribuem para a evasão no Curso Superior de Tecnologia em Gestão Pública do Instituto Federal. A pesquisa de cunho exploratório-descritiva, cujos dados foram coletados a partir de fontes primárias (questionário) e secundárias em um universo de 263 alunos que se evadiram ou cancelaram o Curso Superior de Tecnologia em Gestão Pública, destacou, como principais fatores 
causadores da evasão, a dificuldade em conciliar trabalho e estudo, e a dificuldade em conciliar o Curso Superior de Tecnologia em Gestão Pública com outro curso de graduação.

Junior e Real (2020) realizaram uma pesquisa qualitativa através dos bancos de dados do Instituto Brasileiro de Informação em Ciência e Tecnologia (IBICT) e da Coordenadoria de Aperfeiçoamento de Pessoal de Nível Superior (Capes). Com o intuito de analisar o cenário da produção de dissertações e de teses sobre a evasão na educação superior no período de 2000 a 2018, buscaram identificar se e como o fator institucional é apontado como um dos responsáveis por esse fenômeno nas Instituições de Educação Superior (IES) no Brasil. Concluise que o fator institucional relacionado à evasão tem sido pouco explorado nas pesquisas acadêmicas.

Couto e Santana (2017) realizaram uma pesquisa para diagnosticar as causas de dois problemas enfrentados em universidades brasileiras, a evasão e a retenção. A metodologia dos autores aplica algoritmos de classificação em uma grande base de dados totalizando 175.779 ramos utilizando método Random Forest. Os resultados apontaram que o método Rede Bayesiana atingiu precisão geral de aproximadamente $86 \backslash \%$ sendo considerada uma solução satisfatória para descoberta de conhecimento acerca do desempenho acadêmico dos alunos da graduação, prevendo a evasão.

Oliveira et al. (2019) buscaram identificar as principais causas que levam a desistência e nortear o desenvolvimento de ações que impactem na redução desse fenômeno nas IES do país. A metodologia utilizada foi pesquisa qualitativa, através da análise bibliográfica de artigos científicos, que versam sobre o assunto. Observou-se que, aproximadamente $65 \backslash \%$ dos motivos que levam a evasão estão relacionadas a fatores externos e questões pessoais, enquanto $45 \backslash \%$ referem-se ao ambiente acadêmico.

Fatores econômicos e culturais também podem contribuir com a evasão escolar mediante a dificuldades financeiras ou de adaptação. Além disso, a saúde mental também é estudada com o objetivo de compreender as consequências causadas pela doença. De acordo com Kontoangelos et al. (2020) a pandemia do novo Coronavírus pode causar uma preocupação excessiva e exacerbada pela ansiedade existente. O uso da psiquiatria pode ser benéfico para o acompanhamento não somente de pessoas infectadas, como também de suas famílias ou pessoas próximas.

Sobre impactos da pandemia na educação foi possível identificar 03 trabalhos contendo essa informação em seus conteúdos, de acordo com os autores abaixo: 
Oliveira et al. (2019) buscaram evidenciar como as políticas públicas educacionais, direcionadas ao enfrentamento da pandemia de COVID-19, não levam em consideração a realidade desigual de acesso às TDICs e aos bens sociais, econômicos e culturais de professores e estudantes dos sistemas de educação brasileiros. Um questionário virtual, foi aplicado a estudantes e profissionais da educação do Brasil, os dados foram coletados no período de abril a agosto de 2020. Utilizando o software R-Studio os dados coletados foram codificados e categorizado. Os autores, de acordo com a pesquisa, avaliaram que as políticas públicas educacionais direcionadas ao enfrentamento da pandemia da nova corona vírus, até o momento, não levaram em consideração a realidade da situação da educação brasileira.

Granja et al. (2020) realizaram uma análise sobre os impactos causados pela Covid19 na educação do Brasil, a fim de comparar as diferentes consequências na Rede Pública e Privada de ensino. Utilizou-se para este fim, técnicas de estatística descritiva para descrever e sumarizar os dados obtidos através do Formulário que foi enviado para docentes e discentes, para afirmar ou negar algumas hipóteses levantadas sobre esses fatores. Os resultados apontaram que a falta de aparelho tecnológico e a falta de acesso à internet são dois grandes desafios para os alunos durante a pandemia.

Felippe (2020) buscaram reflexões através de pesquisa de caráter quantitativo sobre a realidade dos alunos nesse período e sobre as consequências das escolhas políticas que podem ser feitas pelos cursos e pelas instituições de ensino superior a partir da aplicação de um questionário sobre as condições de permanência desses alunos em tempos de pandemia. Foi possível identificar que alunos estão em situação de maior dificuldade para arcar com seus gastos regulares. A instituição tentou resolver essa situação por meio de bolsas institucionais emergenciais.

Segundo Senhoras (2020), dentre várias consequências e impactos negativos previstos com a pandemia do COVID-19 sobre a educação, destacam-se o comprometimento do processo de ensino-aprendizagem e o aumento da evasão escolar, pois ambos demandam ações contínuas e estratégicas em um curto espaço de tempo, além dos problemas para a normalização dos ciclos escolares a médio prazo.

\subsection{Pandemia e o novo Coronavírus}


No final de 2019, foi descoberto na cidade de Wuhan, na China, um novo vírus com letalidade considerada baixa, variando entre $0,3 \%$ e $3 \%$, mas com elevada capacidade de transmissão. O vírus, denominado como SARS-CoV-2, causador da COVID-19, se espalhava rapidamente, sendo que, em apenas 30 dias já havia disseminado de uma cidade para o país inteiro, em crescimento exponencial (DIAZ-CASTRILLON; TORO-MONTOYA, 2020; WU; MCGOOGAN, 2020)

No Brasil, o primeiro caso da doença foi notificado em 25 de fevereiro de $2020^{2}$ e o número de contagiados pelo vírus tem crescido, desde então, gradativamente, como pode ser observado na Figura1:

Figura 1 - Casos acumulados de COVID-19 por data de notificação

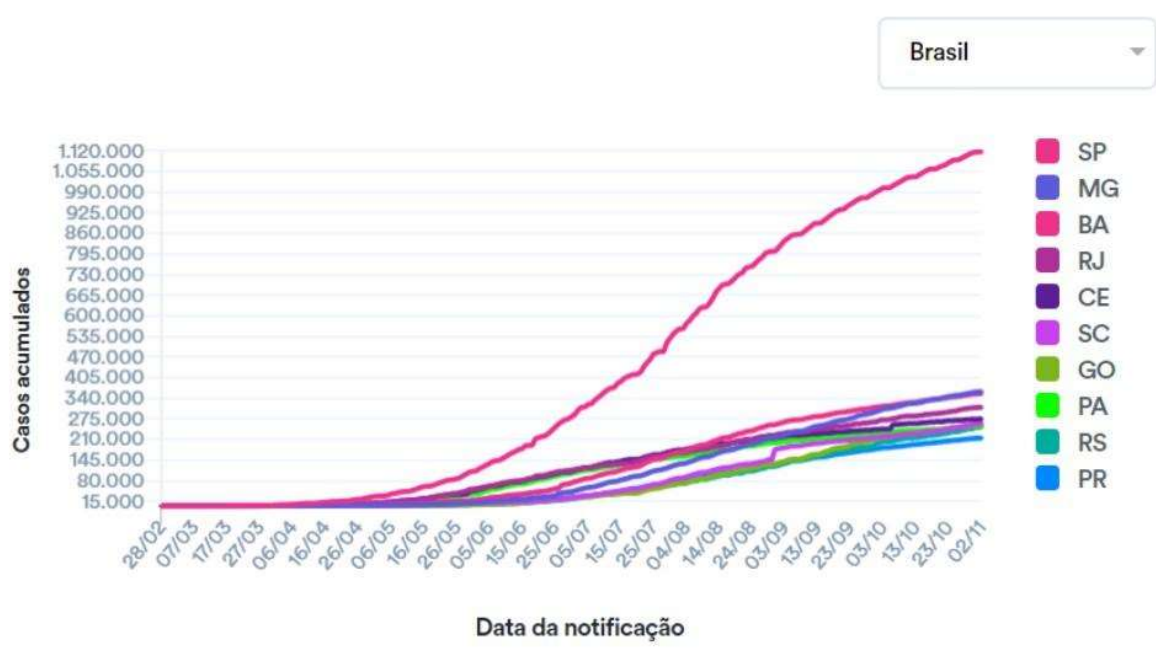

Fonte: Coronavírus Brasil (https://www.gov.br/saude/)

Segundo Santos et al. (2020), a pandemia afetou no contexto mundial, não somente a saúde também aspectos econômicos, sociais e políticos. Na educação 52.898 .349 alunos foram afetados, sendo $52 \backslash \%$ no ensino médio e $20 \backslash \%$ no ensino superior.

\subsection{A Evasão No Ead}

De acordo com o censo EAD.BR ABED (2018), a faixa etária predominante dos estudantes de EaD vai dos 21 aos 30 anos. Para os cursos de pós-graduação, a faixa predominante passa a ser de 31 a 40 anos. A variedade de cursos oferecidos em EaD no Brasil continua expressiva, o que garante uma grande abrangência dessa modalidade de ensino.

\footnotetext{
${ }^{2}$ https://www.gov.br/saude/
} 
No que tange às taxas de evasão, embora continuem sendo uma preocupação para o mercado de EaD, em comparação com os anos anteriores, esses números têm reduzido. Acredita-se que o estudo e o conhecimento das causas da evasão tenham contribuído significativamente com o controle desse fenômeno. Se em 2017, aproximadamente $50 \%$ das instituições com fins lucrativos e públicas federais desconheciam o motivo das evasões, em 2018, como revela o gráfico da Figura 2, o nível de conhecimento aumentou para $88,2 \%$ das instituições que oferecem cursos regulamentados totalmente a distância e conhecem os motivos de evasão.

Figura 2 - Instituições que afirmam conhecer os motivos de evasão por modalidade

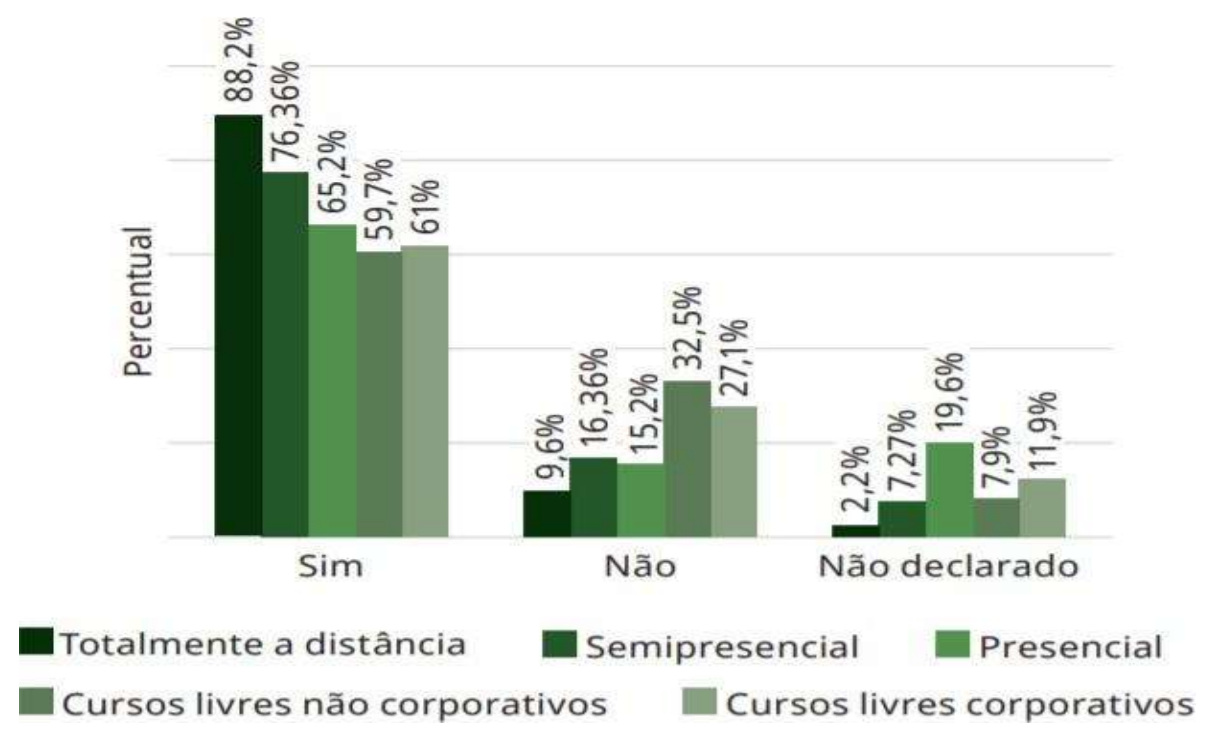

Fonte: Censo (ABED, 2018)

Para Velho (2005), as taxas de evasão estão muito mais associadas à cultura institucional dos programas de pós-graduação, tais como a falta de uma comunidade como referência, seja intelectual ou social, levando o estudante a trabalhar de forma isolada. Ademais, à falta de conhecimento e discussão sobre as normas e expectativas do programa. A autora cita ainda a falta de informação prévia sobre o conteúdo do programa e de orientação sobre o mercado de trabalho futuro.

De acordo com Ferreira et al. (2020), características do aluno e seu relacionamento com a Instituição de Ensino podem interferir em sua permanência ou não no curso escolhido. Os autores realizaram uma pesquisa bibliográfica com o intuito de abranger fatores preditores sobre evasão, destacando que nenhum fator é isolado, porém os que mais se destacam são fatores emocionais e relações com a instituição e equipe pedagógica. 
Contudo, grandes partes referem-se basicamente ao relacionamento entre instituição e aluno. Pouco se considera os fatores externos como grandes influentes na evasão de alunos de programas de pós-graduação.

\section{Materiais e Métodos}

A metodologia aplicada é de cunho quanti-qualitativa buscando compreender a relação do número de evasão de alunos de cursos lato sensu da modalidade EaD e o número de casos de COVID-19 em âmbito nacional.

A coleta de dados de alunos evadidos de cursos de pós-graduação lato sensu na modalidade EaD foi realizada através do banco de dados de uma IES que oferta cursos para alunos de todo o Brasil. A mesma foi escolhida por ter um grande número de alunos matriculados em cursos de pós-graduação, totalizando aproximadamente 300 mil estudantes pela modalidade EaD. Os dados sobre a COVID-19 são fornecidos por sites organizacionais do governo, que fornecem dados como número de casos, mortes, entre outros. Esses dados foram relacionados para identificar a possível relação entre o maior e o menor número de casos de COVID-19 e alunos que evadiram dos cursos no período de 01 de janeiro de 2020 a 17 de novembro de 2020 .

Através do banco de dados da IES foi possível coletar dados de 17.305 alunos que realizaram o cancelamento do curso no período de 01/01/2020 a 17/11/2020. As informações levantadas desses alunos foram: cidade, estado, data de nascimento e sexo (masculino ou feminino). De acordo com o IBGE, o Brasil possui 5.570 municípios. Através do banco de dados Institucional constata-se a existência de alunos em 2685 cidades distintas, sendo 14.075 do sexo feminino e 3.325 do sexo masculino totalizando 17.400 alunos evadidos nesse período.

Sendo valores que ainda crescem constantemente, o número utilizado sobre casos confirmados de COVID-19 nos estados brasileiros foi o total de 6.901 .990 registrados na base nacional na data: 14 de dezembro de 2020.informados pelo do $\mathrm{G} 1^{3}$.

\footnotetext{
${ }^{3}$ https://g1.globo.com
} 


\section{Resultados e Discussão}

Realizou-se inicialmente, análise dos dados coletados em uma instituição de ensino superior provada. A primeira análise foi referente ao número elevado de evasões no ano de 2020 (com pandemia) referente ao ano anterior (2019). A Figura 3 apresenta o somatório das evasões registradas nos dois anos para o mesmo período (janeiro - novembro).

Figura 3 - Aumento de evasões em 2020

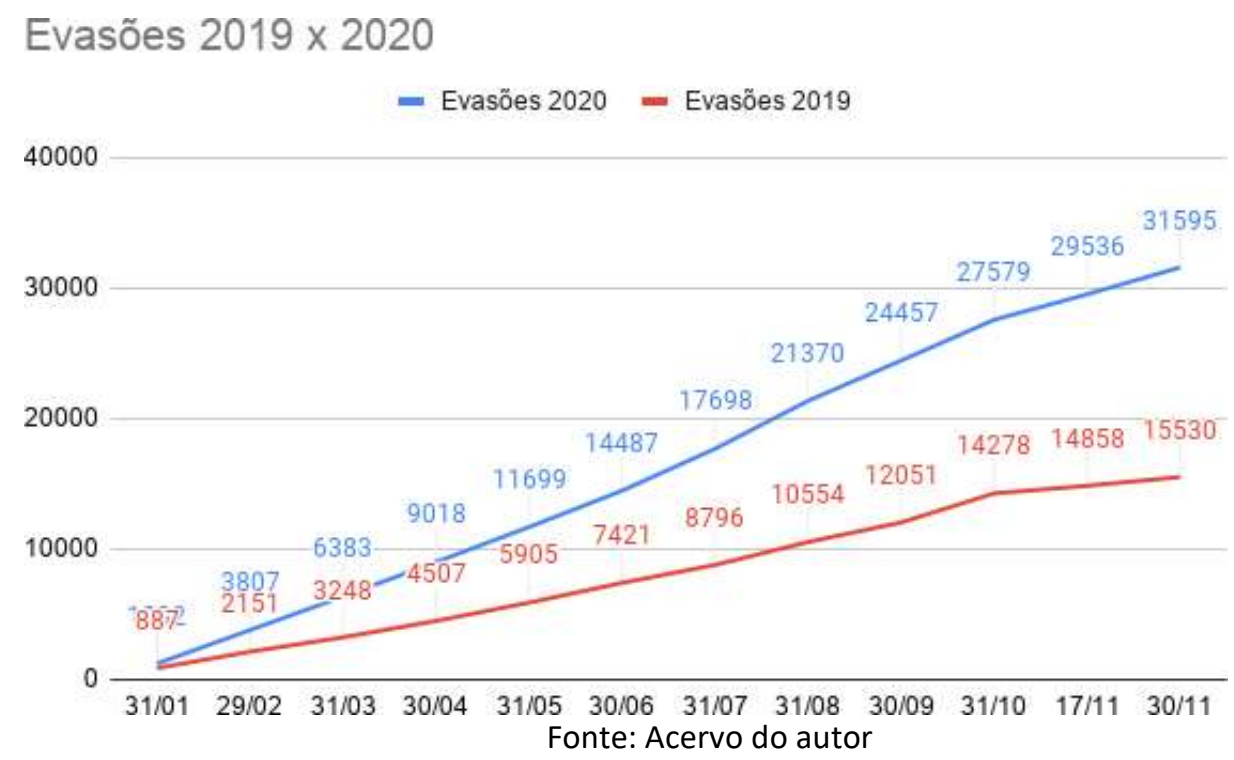

Nota-se que, em ambos os casos, o número de evasões cresceu regularmente ao longo do ano. Além disso, a quantidade de evasões em 2020 esteve sempre próxima do dobro registrado no ano anterior. Paralelamente, o número de casos de COVID registrados ao longo do ano, no mesmo período, é apresentado na figura 4.

Figura 4 - Número de casos de COVID

\section{Casos confirmados de COVID}

8000000

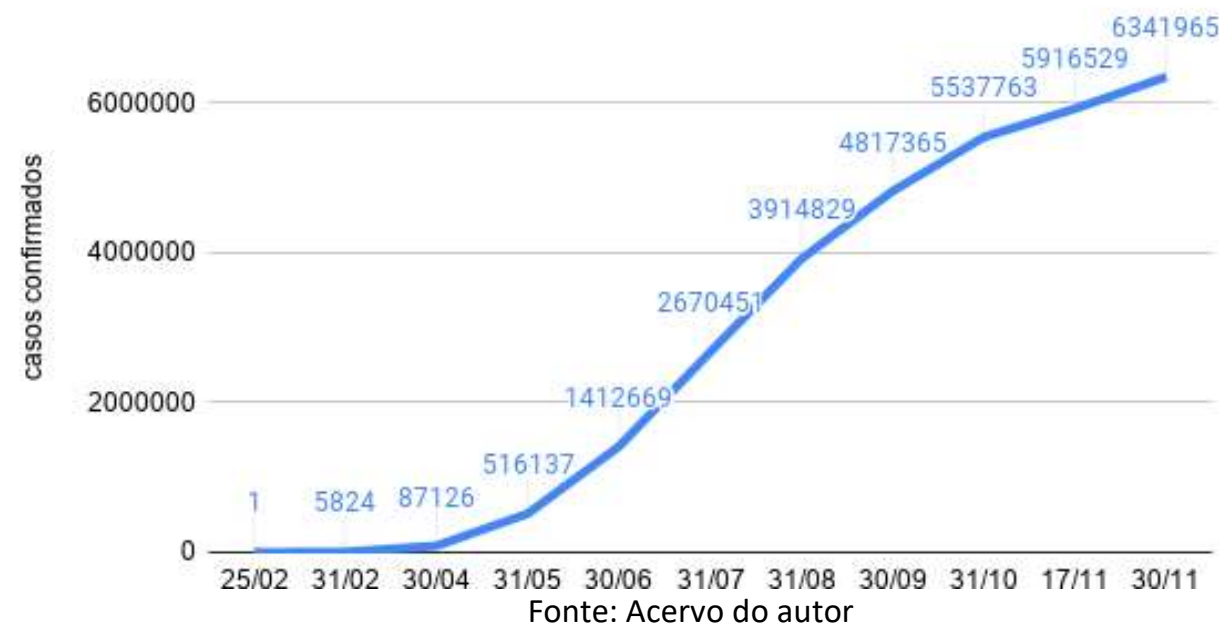


A Figura 5 traz um gráfico com as opções assinaladas por um número de 170 alunos que cancelaram suas matrículas dos cursos de EaD, de uma instituição de ensino privada, num período registrado de novembro de 2018 até novembro de 2019, ou seja, antes da pandemia, mostrando que a situação financeira do aluno também foi um fator que influenciou para a desistência do curso.

Figura 5 - Justificativa por evasão segundo alunos

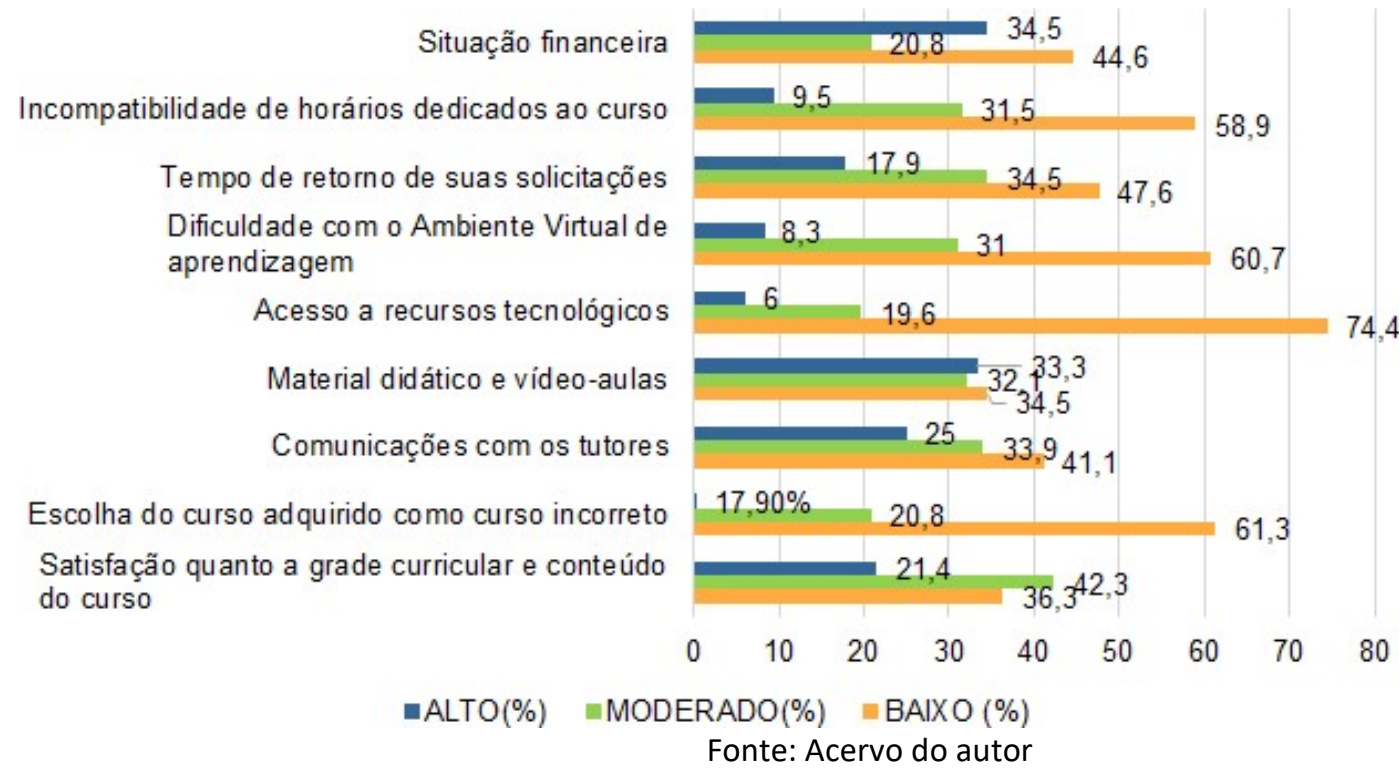

A partir do gráfico exposto na Figura 6 é possível identificar que os maiores índices de desemprego referente ao período de maio a setembro de 2020 foram registrados nos estados da Bahia, Maranhão, Amazonas, Amapá, Alagoas e Rio de Janeiro. Os maiores índices de evasão concentram-se nos estados de São Paulo, Minas Gerais, Rio de Janeiro, Bahia, Ceará e Distrito Federal, de acordo com o período avaliado de janeiro de 2020 a meados de novembro de 2020. Já os estados com maiores números de casos de COVID-19 acumulados até 14 de dezembro de 2020 foram registrados em São Paulo, Minas Gerais, Bahia, Santa Catarina, Rio de Janeiro e Acre. 


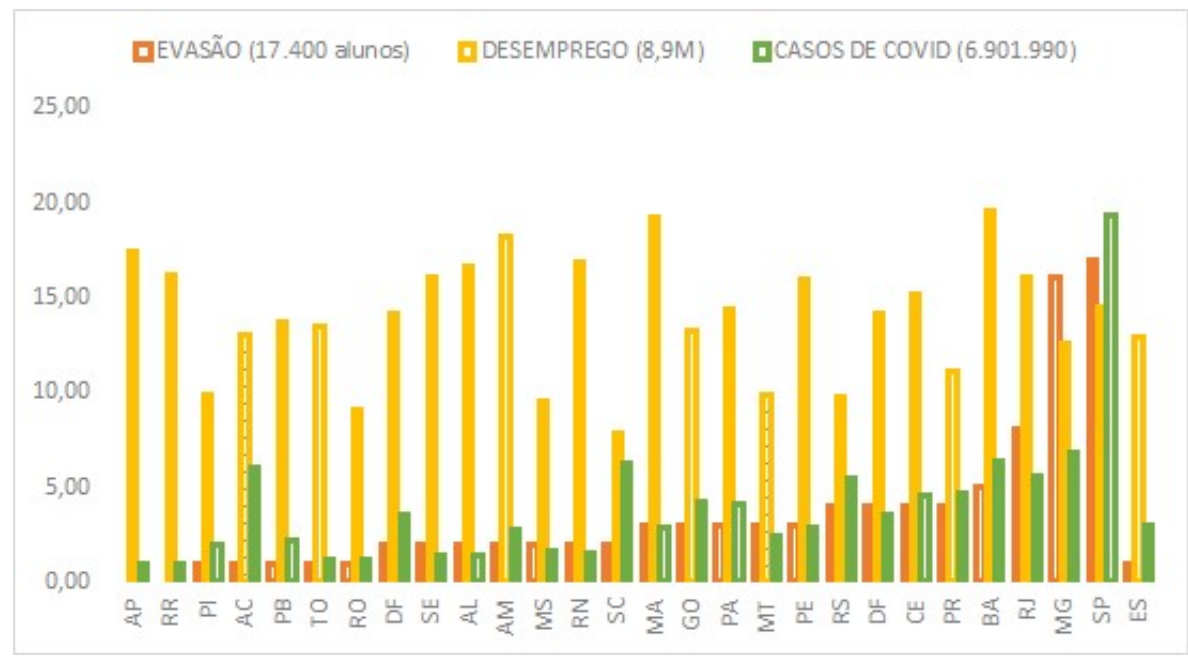

Fonte: Acervo do autor

A partir deste gráfico, os fatores evasão com 17.400 alunos, desemprego com 8,9 milhões e 6.901.990 casos de COVID-19 apresentados possuem valor percentual por estados, apresentando substancialmente taxas mais elevadas nas mesmas regiões, o que pode significar uma correlação entre estados com maior índice de evasão, maior taxa de desemprego e maior número de caso de COVID-19. Segundo Neves et al. (2020)p.4,"aumento do desemprego traduz-se na queda da renda do consumidor", essa afirmação se associa ao abandono escolar privado, uma vez que não terão como manter as mensalidades.

\section{Conclusão}

Através do número de trabalhos relacionados e assuntos abordados em seus conteúdos, foi possível identificar que ainda há poucos trabalhos abordando sobre fatores econômicos como impacto na evasão. Dentre os trabalhos relacionados, foi possível identificar conclusões sobre a evasão na educação presencial e EaD, destacando dificuldades como, o acesso à Internet, Tecnologias de Informação e Comunicação e fatores institucionais como grandes responsáveis para a evasão antes e durante a pandemia. Salienta-se que alunos tiveram que se adaptar totalmente ao ensino remoto, logo, tiveram dificuldades em conciliar trabalho, família e estudo. Crê-se que esses fatores persistem como motivos para evasão, mas entende-se com esse estudo, que há outros fatores que estão envolvidos para esse desfecho no período de pandemia. 
De acordo com os dados institucionais abordados, foi capaz identificar uma possível relação entre taxa de desempregos, números de casos de COVID-19 e evasão em estados semelhantes do Brasil. Porém, esse estudo foi realizado com levantamento de dados de nível nacional relacionado a uma porcentagem de alunos evadidos de apenas uma instituição de Ensino. Afim de confirmar essa afirmação, sugere-se que futuras pesquisas sejam realizadas, investigando dados institucionais e aplicação de questionários a alunos evadidos de outras instituições que ofertem cursos na modalidade EaD, com o intuito de atingir uma maior parte dos estados brasileiros.

\section{REFERÊNCIAS}

ABED. Relatório analítico da aprendizagem a distância no Brasil. [S.I.]: Editora Intersaberes, 2018. v. 1. 215 p.

AMBIEL, Rodolfo Augusto Matteo et al. Motivos de evasão na pós-graduação no Brasil: um instrumento de medida. Interação em Psicologia, v. 24, n. 1, 2020.

ÁVILA, Alinny Luiza Ricco. CAUSAS DA EVASÃO DISCENTE NO CURSO DE ESPECIALIZAÇÃO À DISTÂNCIA EM ENSINO DE SOCIOLOGIA/IFCH/UFRGS. Revista Contraponto, v. 5, n. 1, 2018. BRANCO, Lilian Soares Alves; CONTE, Elaine. EVASÃO NA EDUCAÇÃO A DISTÂNCIA: PRINCÍPIOS E PERSPECTIVAS SOBRE A QUESTÃO. SEFIC 2017, 2017.

BEZERRA, Kelianny Pinheiro et al. Ensino remoto em universidades públicas estaduais: o futuro que se faz presente. Research, Society and Development, v. 9, n. 9, p. e359997226e359997226, 2020.

COUTO, D.; SANTANA, A. Mineração de Dados Educacionais Aplicada à Identificação de Variáveis Associadas à Evasão e Retenção. In: Araújo A.; Rebouças A.; Souza F.; Aguiar Y. II Congresso sobre Tecnologia na Educação. 2017. p. 333-344.

DA SILVA, Adriano Maniçoba; SANTOS, Beatriz Carolini Silva. Eficácia de políticas de acesso ao ensino superior privado na contenção da evasão. Avaliação: Revista da Avaliação da Educação Superior, v. 22, n. 3, p. 741-757, 2017. 
DE OLIVEIRA, Bruna; GUIMARÃES, Lucas José; SANTANA, Thainá Nunes Pires. O CAMINHO PARA A REDUÇÃO DA EVASÃO DE ESTUDANTES NAS INSTITUIÇÕES DE ENSINO SUPERIOR. Humanidades \& Inovação, v. 6, n. 18, p. 155-164, 2019.

DE SOUSA GOMES, Bruna Valéria; BRYTO, Klêner Kleni Costa. A evasão no ensino superior presencial: O curso de Administração da Estácio do Pará, sob o olhar das forças macroambientais de Porter. Revista de Administração e Contabilidade-RAC, v. 5, n. 9, p. 128145, 2018.

DIAS, E; PINTO, F. C. F. A educação e a covid-19. Ensaio: Avaliação e Políticas Públicas em Educação, SciELO Brasil, v. 28, n. 108, p. 545-554, 2020.

DÍAZ-CASTRILLÓN, Francisco Javier; TORO-MONTOYA, Ana Isabel. SARS-CoV-2/COVID-19: el virus, la enfermedad y la pandemia. Medicina y Laboratorio, v. 24, n. 3, p. 183-205, 2020.

FELIPPE, Jonis Manhães Sales. Permanência na educação em tempos de Pandemia: reflexões a partir da licenciatura em Letras do IFF. Revista Tempos E Espaços Em Educação, v. 13, n. 32, p. 69, 2020.

FERNANDES, Eduardo Francisco et al. PANORAMA DO FENÔMENO DA EVASÃO DISCENTE NA PÓS-GRADUAÇÃO: UMA ANÁLISE A PARTIR DO GEOCAPES. 2017.

FERREIRA, Ludmila de Oliveira Amaral et al. Preditores de permanência e evasão em cursos superiores a distância: revisão de literatura. Devir Educação, p. 225-246, 2020.

GONÇALVES, Oldair Luiz; TUDE, João Martins; JUNIOR, Jair Sampaio Soares. Evasão e permanência em cursos superiores de uma Instituição Agrícola-o caso do Campus Alegre do IFES. Revista Cocar, v. 14, n. 28, p. 322-340, 2020.

GUERRA, Lenin Cavalcanti Brito; FERRAZ, Rita Maria Correia; MEDEIROS, Jássio Pereira. Evasão na educação superior de um instituto federal do nordeste brasileiro (Evasion in higher education of a federal institute of the brazilian northeast). Revista Eletrônica de Educação, v. 13, n. 2, p. 533-553, 2019.

JUNIOR, José da Silva Santos; REAL, Giselle Cristina Martins. Fator institucional para a evasão na educação superior. Revista Internacional de Educação Superior, v. 6, p. e020037-e020037, 2020. 
MACIEL, Carina Elisabeth; CUNHA JÚNIOR, Mauro; LIMA, Tatiane da Silva. A produção científica sobre permanência e evasão na educação superior no Brasil. Educação e Pesquisa, v. 45, 2019.

MATTA, Cristiane Maria Barra da; LEBRÃO, Susana Marraccini Giampietri; HELENO, Maria Geralda Viana. Adaptação, rendimento, evasão e vivências acadêmicas no ensino superior: revisão da literatura. Psicologia Escolar e Educacional, v. 21, n. 3, p. 583-591, 2017.

OLIVEIRA, Pedro Rodrigues de; OESTERREICH, Silvia Aparecida; ALMEIDA, Vera Luci de. Evasão na pós-graduação a distância: evidências de um estudo no interior do Brasil. Educação e Pesquisa, v. 44, 2018.

PIMENTEL, Fernando Silvio Cavalcante; DE FRANÇA LIMA, Mônica Rejane. Evasão na EAD: o caso do curso de pós-graduação em EDHDI/UFAL. Debates em Educação, v. 10, n. 21, p. 185199, 2018.

SILVA, Vinícius Delfino; PASSOS, Marize Lyra Silva; NOBRE, Isaura Alcina Martins. EVASÃO NA EDUCAÇÃO A DISTÂNCIA: AS CAUSAS DO ABANDONO EM UM CURSO DE PÓS-GRADUAÇÃO LATO SENSU. Revista Ifes Ciência, v. 5, n. 2, p. 114-124, 2019.

SOUSA, Andréia da Silva Quintanilha; MACIEL, Carina Elisabeth. Expansão da educação superior: permanência e evasão em cursos da Universidade Aberta do Brasil. Educação em Revista, v. 32, n. 4, p. 175-204, 2016.

VELLOZO, Sarah Rachel Gonczarowska et al. Evasão na educação a distância: uma revisão sistemática. Revista EDaPECI, v. 19, n. 3, p. 85-94, 2019. 